\title{
THEORITICAL REVIEW : TEORI PERBEDAAN GENERASI
}

\author{
Oleh \\ Yanuar Surya Putra \\ Dosen Tetap STIE AMA Salatiga
}

\begin{abstract}
The difference in the generation of work environments has become a subject always emerging in the development of human resource management, and the concept of generation differences continues to evolve over time. In the last few years the definition of generation has developed, one of which is the definition by Kupperschmidt's (2000) which says that the generation is a group of individuals who identify the group based on the same year of birth, age, location, and events in the life of that individual group that has significant influence In their growth phase. The results of this study indicate that there are significant differences in characteristics between generations $Z$ with other generations, one of the main factors that distinguish is the mastery of information and technology. For the $Z$ generation information and technology are things that have become part of their lives, because they are born where access to information, especially the Internet has become a global culture, so that it affects their values, views and life goals. The rise of the $Z$ generation will also pose new challenges to management practices within organizations, especially for human resource management practices.
\end{abstract}

Keywords : Generational differences, Generation X, Generation Y, Generation Z

\section{PENDAHULUAN}

Perbedaan generasi dalam lingkungan kerja menjadi salah subyek yang selalu muncul dalam perkembangan manajemen sumber daya manusia, dan konsep perbedaan generasi terus berkembang dari waktu ke waktu. Penelitian yang pertama tentang perkembangan nilai - nilai generasi dilakukan oleh Manheim pada tahun 1952, penelitian tersebut didasarkan pada tulisan - tulisan dalam bidang sosiologi tentang generasi pada kisaran tahun 1920 sampai dengan tahun 1930. Mannheim (1952) mengungkapkan bahwa generasi yang lebih muda 
tidak dapat bersosialisasi dengan sempurna karena adanya gap antara nilai - nilai ideal yang diajarkan oleh generasi yang lebih tua dengan realitas yang dihadapi oleh generasi muda tersebut, lebih lanjut dikatakan bahwa lokasi sosial memiliki efek yang besar terhadap terbentuknya kesadaran individu.

Menurut Manheim (1952) generasi adalah suatu konstruksi sosial dimana didalamnya terdapat sekelompok orang yang memiliki kesamaan umur dan pengalaman historis yang sama. Lebih lanjut Manheim (1952) menjelaskan bahwa individu yang menjadi bagian dari satu generasi, adalah mereka yang memiliki kesamaan tahun lahir dalam rentang waktu 20 tahun dan berada dalam dimensi sosial dan dimensi sejarah yang sama. Definisi tersebut secara spesifik juga dikembangkan oleh Ryder (1965) yang mengatakan bahwa generasi adalah agregat dari sekelompok individu yang mengalami peristiwa - peristiwa yang sama dalam kurun waktu yang sama pula.

Dalam beberapa tahun terakhir definisi generasi telah berkembang, salah satunya adalah definisi menurut Kupperschmidt's (2000) yang mengatakan bahwa generasi adalah sekelompok individu yang mengidentifikasi kelompoknya berdasarkan kesamaan tahun kelahiran, umur, lokasi, dan kejadian - kejadian dalam kehidupan kelompok individu tersebut yang memiliki pengaruh signifikan dalam fase pertumbuhan mereka. Dari beberapa definisi tersebut teori tetang perbedaan generasi dipopulerkan oleh Neil Howe dan William Strauss pada tahun 1991. Howe \& Strauss (1991, 2000) membagi generasi berdasarkan kesamaan rentang waktu kelahiran dan kesamaan kejadian - kejadian historis. Pembagian generasi tersebut juga banyak dikemukakan oleh peneliti - peneliti lain dengan 
label yang berbeda - beda, tetapi secara umum memiliki makna yang sama.

Sebagai contoh menurut Martin \& Tulgan (2002) Generasi Y adalah generasi yang lahir pada kisaran tahun 1978, sementara menurut Howe \& Strauss (2000) generasi Y adalah generasi yang lahir pada tahun 1982, hal tersebut terjadi karena adanya perbedaan skema yang digunakan untuk mengelompokkan generasi tersebut, karena peneliti - peneliti tersebut berasal dari Negara yang berbeda. Beberapa pendapat tentang pebedaan generasi dapat dilihat pada tabel berikut :

\section{Tabel 1 \\ Pengelompokan Generasi}

\begin{tabular}{|c|c|c|c|c|c|}
\hline Sumber & & & Label & & \\
\hline Tapscott (1998) & - & $\begin{array}{c}\text { Baby Boom } \\
\text { Generation } \\
(1946-1964)\end{array}$ & $\begin{array}{c}\text { Generation X } \\
(1965-1975)\end{array}$ & $\begin{array}{c}\text { Digital } \\
\text { Generation } \\
(1976-2000)\end{array}$ & - \\
\hline $\begin{array}{c}\text { Howe \& Strauss } \\
\qquad(2000)\end{array}$ & $\begin{array}{c}\text { Silent } \\
\text { Generation } \\
(1925-1943)\end{array}$ & $\begin{array}{c}\text { Boom } \\
\text { Generation } \\
(1943-1960)\end{array}$ & $\begin{array}{c}13^{\text {th }} \text { Generation } \\
(1961-1981)\end{array}$ & $\begin{array}{c}\text { Millenial } \\
\text { Generation } \\
(1982-2000)\end{array}$ & - \\
\hline $\begin{array}{l}\text { Zemke et al } \\
\qquad(2000)\end{array}$ & $\begin{array}{c}\text { Veterans } \\
(1922-1943)\end{array}$ & $\begin{array}{c}\text { Baby Boomers } \\
(1943-1960)\end{array}$ & $\begin{array}{c}\text { Gen-Xers } \\
(1960-1980)\end{array}$ & $\begin{array}{c}\text { Nexters } \\
(1980-1999)\end{array}$ & - \\
\hline $\begin{array}{c}\text { Lancaster \& Stillman } \\
\text { (2002) }\end{array}$ & $\begin{array}{l}\text { Traditionalist } \\
(1900-1945)\end{array}$ & $\begin{array}{l}\text { Baby Boomers } \\
(1946-1964)\end{array}$ & $\begin{array}{c}\text { Generation Xers } \\
(1965-1980)\end{array}$ & $\begin{array}{l}\text { Generation Y } \\
(1981-1999)\end{array}$ & - \\
\hline $\begin{array}{c}\text { Martin \& Tulgan } \\
\text { (2002) }\end{array}$ & $\begin{array}{c}\text { Silent } \\
\text { Generation } \\
(1925-1942)\end{array}$ & $\begin{array}{c}\text { Baby Boomers } \\
(1946-1964)\end{array}$ & $\begin{array}{c}\text { Generation X } \\
(1965-1977)\end{array}$ & $\begin{array}{l}\text { Millenials } \\
(1978-2000)\end{array}$ & - \\
\hline $\begin{array}{c}\text { Oblinger \& Oblinger } \\
(2005)\end{array}$ & $\begin{array}{l}\text { Matures } \\
(<1946)\end{array}$ & $\begin{array}{c}\text { Baby Boomers } \\
(1947-1964)\end{array}$ & $\begin{array}{c}\text { Generation Xers } \\
(1965-1980)\end{array}$ & $\begin{array}{l}\text { Gen-Y/NetGen } \\
(1981-1995)\end{array}$ & $\begin{array}{c}\text { Post Millenials } \\
\text { (1995-present }\end{array}$ \\
\hline
\end{tabular}

\section{Bagaimana Pengelompokan Generasi Terbentuk ?}

Pemahaman dasar mengenai pengelompokan generasi adalah adanya premis bahwa generasi adalah sekelompok individu yang dipengaruhi oleh kejadian - kejadian bersejarah dan fenomena budaya yang terjadi dan dialami pada fase kehidupan mereka (Nobel \& Schewe, 2003; Twenge, 2000), dan 
kejadian serta fenomena tersebut menyebabkan terbentuknya ingatan secara kolektif yang berdampak dalam kehidupan mereka (Dencker et al. 2008). Jadi kejadian historis, sosial, dan efek budaya bersama dengan faktor-faktor lain ini akan berpengaruh terhadap terbentuknya perilaku individu, nilai, dan kepribadian (Caspi \& Roberts, 2001; Caspi et.al, 2005).

Dari penjelasan tersebut ada 2 hal utama yang mendasari pengelompokan generasi, yaitu faktor demografi khususnya kesamaan tahun kelahiran dan yang kedua adalah faktor sosiologis khususnya adalah kejdian - kejadian yang historis, menurut Parry \& Urwin (2011) faktor kedua lebih banyak dipakai sebagai dasar dalam studi maupun penelitian tentang perbedaan generasi. Para ahli berpendapat bahwa generasi terbentuk lebih disebabkan karena kejadian atau event yang bersejarah dibanding dengan tahun kelahiran, sebagai contoh dalam tabel 1 dapat dilihat bahwa generasi Baby Boom dimulai pada rentang waktu dari tahun 1943 sampai dengan 1946 dan berakhir pada rentang waktu 1960 sampai dengan 1969. Generasi X dimulai dari rentang waktu yang bervariasi, yaitu dari tahun 1961 sampai dengan tahun 1965 dan berakhir pada tahun 1975 sampai dengan 1981.

Menurut Howe \& Strauss (2000), ada tiga atribut yang lebih jelas mengidentifikasi generasi dibanding dengan tahun kelahiran, atribut tersebut antara lain :

1. Percieved membership : persepsi individu terhadap sebuah kelompok dimana mereka tergabung didalamnya, khususya pada masa - masa remaja sampai dengan masa dewasa muda. 
2. Common belief and behaviors : sikap terhadap keluarga, karir, kehidupan personal, politik, agama dan pilihan - pilihan yang diambil terkait dengan pekerjaan, pernikahan, anak, kesehatan, kejahatan.

3. Common location in history : perubahan pandangan politik, kejadian yang bersejarah, contohnya seperti : perang, bencana alam, yang terjadi pada masa - masa remaja sampai dengan dewasa muda.

Adanya perbedaan lokasi dan perbedaan kejadian yang bersejarah karena perbedaan letak geografis juga menjadi salah hal yang menjadi perdebatan dalam pengelompokan generasi, menurut Parry \& Uwin, (2010) karena konseptualisasi pengelompokan generasi seringkali berbasis event bersejarah di Amerika Serikat, perlu adanya generalisasi basis pengelompokan generasi yang dapat diterima di semua tempat. Dalam perkembangannya para peneliti telah mengadopsi label yang sama dalam pengelompokan generasi, walaupun masih ada beberapa perbedaan terkait dengan kapan dimulainya sebuah kelompok generasi dan kapan berakhirnya.

\section{PERKEMBANGAN TEORI PERBEDAAN GENERASI}

Dalam literatur tentang perbedaan generasi digunakan kriteria yang umum dan bisa diterima secara luas diberbagai wilayah, dalam hal ini kriteria yang dipakai adalah tahun kelahiran dan peristiwa - peristiwa yang terjadi secara global (Twenge, 2006). Beberapa hasil penelitian secara konsisten membandingkan perbedaan generasi, dengan sampel mulai dari tahun 1950an sampai dengan awal tahun 2000, menunjukkan perbedaan karakteristik dari 3 kelompok generasi, yaitu generasi baby boomers, generasi X dan generasi Y (Millennial), salah satunya 
adalah penelitian dari Lancaster \& Stillman (2002), yang memberikan hasil sebagai berikut :

Tabel 2

Perbedaan Generasi (Lancaster \& Stillman)

\begin{tabular}{|c|c|c|c|}
\hline Faktor & Baby Boomers & Generation Xers & Millennial Generation \\
\hline Attitude & Optimis & Skeptis & Realistis \\
\hline Overview & $\begin{array}{l}\text { Generasi ini percaya pada } \\
\text { adanya peluang, dan seringkali } \\
\text { terlalu idealis untuk membuat } \\
\text { perubahan positif didunia. } \\
\text { Mereka juga kompetitif dan } \\
\text { mencari cara untuk melakukan } \\
\text { perubahan dari sistem yang } \\
\text { sudah ada. }\end{array}$ & $\begin{array}{l}\text { Generasi yang tertutup, } \\
\text { sangat independen dan } \\
\text { punya potensi, tidak } \\
\text { bergantung pada orang } \\
\text { lain untuk menolong } \\
\text { mereka }\end{array}$ & $\begin{array}{l}\text { Sangat menghargai } \\
\text { perbedaan, lebih } \\
\text { memilih bekerja sama } \\
\text { daripada menerima } \\
\text { perintah, dan sangat } \\
\text { pragmatis } \\
\text { memecahkan persoalan }\end{array}$ \\
\hline $\begin{array}{c}\text { Work } \\
\text { habits }\end{array}$ & $\begin{array}{l}\text { Punya rasa optimis yang tinggi, } \\
\text { pekerja keras yang } \\
\text { menginginkan penghargaan } \\
\text { secara personal, percaya pada } \\
\text { perubahan dan perkembangan } \\
\text { diri sendiri }\end{array}$ & 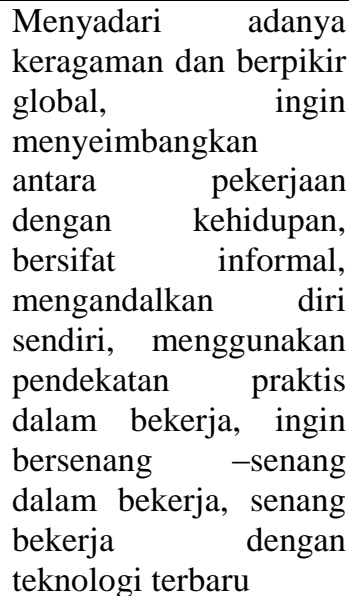 & $\begin{array}{l}\text { Memiliki rasa optimis } \\
\text { yang tinggi, fokus } \\
\text { pada prestasi, percaya } \\
\text { diri, percaya pada } \\
\text { nilai-nilai moral dan } \\
\text { sosial, menghargai } \\
\text { adanya keragaman }\end{array}$ \\
\hline
\end{tabular}

Hasil penelitian lain menunjukkan hasil yang secara umum memiliki kesamaan. Veteran generation atau sering juga disebut sebagai silent generation adalah generasi yang konservatif dan disiplin (Howe \& Strauss, 1991), Baby boom generation adalah generasi yang materialistis dan berorientasi waktu (Howe \& Strauss, 1991).

Generasi X adalah generasi yang lahir pada tahun - tahun awal dari perkembangan teknologi dan informasi seperti penggunaan PC (personal 
computer), video games, tv kabel, dan internet. Ciri - ciri dari generasi ini adalah: mampu beradaptasi, mampu menerima perubahan dengan baik dan disebut sebagai generasi yang tangguh, memiliki karakter mandiri dan loyal, sangat mengutamakan citra, ketenaran, dan uang, tipe pekerja keras, menghitung kontribusi yang telah diberikan perusahaan terhadap hasil kerjanya (Jurkiewicz, 2000).

Generasi Y dikenal dengan sebutan generasi millenial atau milenium. Ungkapan generasi Y mulai dipakai pada editorial koran besar Amerika Serikat pada Agustus 1993. Generasi ini banyak menggunakan teknologi komunikasi instan seperti email, SMS, instant messaging dan media sosial seperti facebook dan twitter, dengan kata lain generasi $\mathrm{Y}$ adalah generasi yang tumbuh pada era internet booming (Lyons, 2004). Lebih lanjut (Lyons, 2004) mengungkapkan ciri - ciri dari generasi Y adalah: karakteristik masing-masing individu berbeda, tergantung dimana ia dibesarkan, strata ekonomi, dan sosial keluarganya, pola komunikasinya sangat terbuka dibanding generasi-generasi sebelumnya, pemakai media sosial yang fanatik dan kehidupannya sangat terpengaruh dengan perkembangan teknologi, lebih terbuka dengan pandangan politik dan ekonomi, sehingga mereka terlihat sangat reaktif terhadap perubahan lingkungan yang terjadi di sekelilingnya, memiliki perhatian yang lebih terhadap kekayaan.

\section{Bangkitnya Generasi Z}

Kemajuan jaman juga menyebabkan komposisi penduduk tiap generasi akan berubah, komposisi kelompok baby boomers mulai menurun, jika terkait dengan usia produktif dan komposisi angkatan kerja maka jumlah kelompok generasi $\mathrm{X}$ 
dan Y yang terbanyak. Selain itu mulai bangkit generasi yang mulai memasuki angkatan kerja yang disebut dengan generasi Z. Penelitian Bencsik, Csikos, dan Juhez (2016) menunjukkan masuknya Generasi Z didalam kelompok generasi, yang dapat dilihat dalam tabel berikut:

Tabel 3

\section{Perbedaan Generasi}

\begin{tabular}{cc}
\hline Tahun Kelahiran & Nama Generasi \\
\hline $\mathbf{1 9 2 5}-\mathbf{1 9 4 6}$ & Veteran generation \\
$\mathbf{1 9 4 6}-\mathbf{1 9 6 0}$ & Baby boom generation \\
$\mathbf{1 9 6 0}-\mathbf{1 9 8 0}$ & X generation \\
$\mathbf{1 9 8 0}-\mathbf{1 9 9 5}$ & Y generation \\
$\mathbf{1 9 9 5}-\mathbf{2 0 1 0}$ & Z generation \\
$\mathbf{2 0 1 0}+$ & Alfa generation \\
\hline
\end{tabular}

Enam kelompok generasi tersebut memiliki karakteristik yang berbeda beda. Generasi paling muda yang baru memasuki angkatan kerja adalah generasi $\mathrm{Z}$, disebut juga iGeneration atau generasi internet. Generasi Z memiliki kesamaan dengan generasi $\mathrm{Y}$, tapi generasi $\mathrm{Z}$ mampu mengaplikasikan semua kegiatan dalam satu waktu (multi tasking) seperti: menjalankan sosial media menggunakan ponsel, browsing menggunakan PC, dan mendengarkan musik menggunakan headset. Apapun yang dilakukan kebanyakan berhubungan dengan dunia maya. Sejak kecil generasi ini sudah mengenal teknologi dan akrab dengan gadget canggih yang secara tidak langsung berpengaruh terhadap kepribadian.

Forbes Magazine membuat survei tentang generasi $\mathrm{Z}$ di Amerika Utara dan Selatan, di Afrika, di Eropa, di Asia dan di Timur Tengah. 49 ribu anak-anak ditanya (Dill,2015). Atas dasar hasil itu dapat dikatakan bahwa generasi Z adalah generasi global pertama yang nyata. Teknologi tinggi dalam darah mereka, 
mereka telah tumbuh di lingkungan yang tidak pasti dan kompleks yang menentukan pandangan mereka tentang pekerjaan, belajar dan dunia. Mereka memiliki harapan yang berbeda di tempat kerja mereka, berorientasi karir, generasi profesional yang ambisius, memiliki kemampuan teknis-dan pengetahuan bahasa pada tingkat tinggi. Oleh karena itu, mereka tenaga kerja yang sangat baik. Pengusaha harus mempersiapkan untuk terlibat generasi Z karena mereka adalah karyawan yang efektif di era digital (Elmore, 2014).

Hasil penelitian dari Bencsik \& Machova (2016) menunjukkan perbedaan karakteristik generasi $\mathrm{Z}$ dengan generasi - generasi sebelumnya, hasil tersebut dapat dilihat pada tabel berikut:

Tabel 4

Generational behavioural characteristics of different age-groups Bencsik \& Machova, 2016.

\begin{tabular}{|c|c|c|c|c|}
\hline Factors & Baby - boom & $\mathrm{X}$ generation & Y generation & Z generation \\
\hline View & $\begin{array}{l}\text { Communal, } \\
\text { unified think } \\
\text { ing }\end{array}$ & $\begin{array}{l}\text { Self-centred and } \\
\text { medium-term }\end{array}$ & $\begin{array}{l}\text { Egotistical, short } \\
\text { term }\end{array}$ & $\begin{array}{l}\text { No sense of } \\
\text { commitment, be } \\
\text { happy with what } \\
\text { you have and live } \\
\text { for the present }\end{array}$ \\
\hline $\begin{array}{l}\text { Relation } \\
\text { ship }\end{array}$ & $\begin{array}{l}\text { First and fore } \\
\text { most personal }\end{array}$ & $\begin{array}{l}\text { Personal and vir } \\
\text { tual networks }\end{array}$ & $\begin{array}{l}\text { Principally vir } \\
\text { tual, network }\end{array}$ & $\begin{array}{l}\text { Virtual and su } \\
\text { perficial }\end{array}$ \\
\hline Aim & Solid existence & $\begin{array}{l}\text { Multi-environ } \\
\text { ment, secure } \\
\text { position }\end{array}$ & $\begin{array}{l}\text { Rivalry for leader } \\
\text { position }\end{array}$ & $\begin{array}{l}\text { Live for the } \\
\text { present }\end{array}$ \\
\hline $\begin{array}{l}\text { Self } \\
\text { realization }\end{array}$ & $\begin{array}{l}\text { Conscious car } \\
\text { rier building }\end{array}$ & Rapid promotion & Immediate & $\begin{array}{l}\text { Questions the } \\
\text { need for it at all }\end{array}$ \\
\hline IT & $\begin{array}{l}\text { It is based on } \\
\text { self-instruction } \\
\text { and incomplete }\end{array}$ & $\begin{array}{l}\text { Uses with confi } \\
\text { dence }\end{array}$ & $\begin{array}{l}\text { Part of its every } \\
\text { day life }\end{array}$ & Intuitive \\
\hline Values & $\begin{array}{l}\text { Patience, soft } \\
\text { skills, respect } \\
\text { for traditions, } \\
\text { EQ, hard work, }\end{array}$ & $\begin{array}{l}\text { Hard work, open } \\
\text { ness, respect for } \\
\text { diversity, curios } \\
\text { ity, practicality }\end{array}$ & $\begin{array}{l}\text { Flexibility, mobil } \\
\text { ity, broad but } \\
\text { superficial knowl } \\
\text { edge, success } \\
\text { orientation, crea } \\
\text { tivity, freedom of } \\
\text { information takes } \\
\text { priority }\end{array}$ & $\begin{array}{l}\text { Live for the } \\
\text { present, rapid } \\
\text { reaction to eve } \\
\text { rything, initiator, } \\
\text { brave, rapid infor } \\
\text { mation access and } \\
\text { content search }\end{array}$ \\
\hline
\end{tabular}




\begin{tabular}{|c|c|c|c|c|}
\hline $\begin{array}{l}\text { Other } \\
\text { possible } \\
\text { charac } \\
\text { teristics }\end{array}$ & $\begin{array}{l}\text { Respect for } \\
\text { hierarchy, exag } \\
\text { gerated mod } \\
\text { esty or arrogant } \\
\text { inflexibility, } \\
\text { passivity, cyni } \\
\text { cism, disap } \\
\text { pointment }\end{array}$ & $\begin{array}{l}\text { Rule abiding, } \\
\text { materialistic, fair } \\
\text { play, less respect } \\
\text { for hierarchy, has } \\
\text { a sense of } \\
\text { relativity, need to } \\
\text { prove themselves }\end{array}$ & $\begin{array}{l}\text { Desire for } \\
\text { independence, } \\
\text { no respect for } \\
\text { tradition, quest } \\
\text { for new forms } \\
\text { of knowledge, } \\
\text { inverse socializa } \\
\text { tion, arrogant, } \\
\text { home office and } \\
\text { part-time work, } \\
\text { interim manage } \\
\text { ment, undervalue } \\
\text { soft skills and EQ }\end{array}$ & $\begin{array}{l}\text { Differing view } \\
\text { points, lack of } \\
\text { thinking, hap } \\
\text { piness, pleasure, } \\
\text { divided attention, } \\
\text { lack of conse } \\
\text { quential thinking, } \\
\text { no desire to make } \\
\text { sense of things, } \\
\text { the boundaries of } \\
\text { work and enter } \\
\text { tainment overlap, } \\
\text { feel at home } \\
\text { anywhere }\end{array}$ \\
\hline
\end{tabular}

Hasil penelitian tersebut menunjukkan bahwa ada perbedaan karakteristik yang signifikan antar generasi $\mathrm{Z}$ dengan generasi lain, salah satu faktor utama yang membedakan adalah penguasaan informasi dan teknologi. Bagi generasi $\mathrm{Z}$ informasi dan teknologi adalah hal yang sudah menjadi bagian dari kehidupan mereka, karena mereka lahir dimana akses terhadap informasi, khususnya internet sudah menjadi budaya global, sehingga hal tersebut berpengaruh terhadap nilai nilai, pandangan dan tujuan hidup mereka. Bangkitnya generasi $\mathrm{Z}$ juga akan menimbulkan tantangan baru bagi praktek manajemen dalam organisasi, khususnya bagi praktek manajemen sumber daya manusia. 


\section{DAFTAR PUSTAKA}

Bencsik, A., Csikos, G., \& Juhaz, T. (2016). Y and Z Generations at Workplaces. Journal of Competitiveness, 8(3), 90-106. https://doi.org/10.7441/joc.2016.03.06

Bencsik, A., \& Machova, R. (2016, April). Knowledge Sharing Problems from the Viewpoint of Intergeneration Management. In ICMLG2016 - 4th International Conferenceon Management, Leadership and Governance: ICMLG2016 (p.42). Academic Conferences andpublishing limited.

Caspi, A., \& Roberts, B. W. (2001). Personality development across the life course: The argument for change and continuity. Psychological Inquiry, 12(2), 49-66. doi:10.1207/S15327965 PLI1202_01.

Caspi, A., Roberts, B. W., \& Shiner, R. L. (2005). Personality development: Stability and change. Annual Review of Psychology, 56, 453-484. doi:10.1146/annurev.psych.55.090902.141913.

Dencker, J. C., Joshi, A., \& Martocchio, J. J. (2008). Towards a theoretical framework linking generational memories to workplace attitudes and behaviors. Human Resource Management Review, 18(3), 180-187. doi:10.1016/j.hrmr.2008.07.007.

Dill, K. (2015). 7 Things Employers Should Know About The Gen Z Workforce, Forbes Magazin, 11.6. Retrieved March 16, 2016, from http://www.forbes.com/sites/kathryndill/2015/11/06/7-thingsemployers-shouldknow-about-the-gen-z-workforce/print/.

Elmore, T. (2014). How Generation Z Differs from Generation Y. Retrieved July 01, 2015, fromhttp://growingleaders.com/blog/generation-z-differs-generation-y/.

Howe, N., \& Strauss, W. (1991). Generations: the history of America's future, 1584 to 2069.

Howe, N., \& Strauss, W. (2000). Millennials rising: The next great generation. New York: Vintage.

Jurkiewicz, C. L. (2000). Generation X and the Public Employee. Public Personnel Management, 29(1), 55. https://doi.org/10.1177/009102600002900105

Lancaster, L. C. and Stillman, D. (2002). When Generations Collide. Who They Are. Why They Clash. How to Solve the Generational Puzzle at Work. New York: Collins Business.* 
Lyons, S. (2004). An exploration of generational values in life and at work. ProQuest Dissertations and Theses, 441-441 . Retrieved from http://ezproxy.um.edu.my/docview/305203456?accountid=28930

Mannheim, K. (1952). The Problem of Generations. Essays on the Sociology of Knowledge, 24(19), 276-322-24.

Martin, C. A. and Tulgan, B. (2002). Managing the Generational Mix. Amherst, MA: HRD Press.

Noble, S. M., \& Schewe, C. D. (2003). Cohort segmentation: An exploration of its validity. Journal of Business Research, 56(12), 979-987. doi:10.1016/S0148-2963(02)00268-0.

Parry, E., \& Urwin, P. (2010). Generational differences in work values: A review of theory and evidence. International Journal of Management Reviews, 13, 79-96. doi:10.1111/j.1468-2370. 2010.00285.x.

Oblinger, D. and Oblinger, J., Eds. (2005). Educating the Net Gen. Washington, D.C.: EDUCAUSE.

Ryder, N. B. (1965). The Cohort as a Concept in the Study of Social Change. American Sociological Review, 30(6), 843-861. https://doi.org/10.2307/2090964

Strauss, W., \& Howe, N. (1991). Generations: The history of America's future, 1584 to 2069. New York: William Morrow \& Co.

Twenge, J. M. (2006). Generation Me: Why Today's Young Americans Are More Confident, Assertive, Entitled-and More Miserable Than Ever Before. New York: Free Press 